\title{
FUNERAL CONSUMPTION AS AN AMBIVALENT EXPERIENCE
}

Isabelle Szmigin, University of Birmingham, UK

Louise Canning, University of Birmingham, UK

\begin{abstract}
Consumption experience (Holbrook and Hirschman 1982) is widely used in the marketing literature although mostly within the broad context of service (Lusch and Vargo, 2006; Pine and Gilmore, 1999) or hedonic experience (Arnould and Price, 1993). Holbrook and Hirschman (1982) provide an alternative to consumers as logical thinkers, rather interpreting consumption as an activity through which an individual experiences multi-sensory fantasies and fun. Such experiential, as opposed to functional consumption, is reflected in academic and practitioner interest in understanding emotional responses resulting from consumer interaction with various stimuli (other consumers, marketer, product, service) and in determining how to ensure memorable (Pine and Gilmore, 1999) or extraordinary (LaSalle and Britton 2003) experiences. Carù and Cova (2003), however, suggest that thinking around consumption experience should go beyond what they refer to as an ideological view of experience as extraordinary. This leads us also to consider the nature of lived experience as including ambivalence (Otnes, 1996). Every day and extraordinary experiences result in many responses and the association of experience and ambivalence is as yet underdeveloped theoretically. In particular the experience described in this paper engages with the idea of psychological and social ambivalence. In so doing, overload and role conflict are explored as antecedents to ambivalence The paper finds that the experience of funeral arrangement and consumption emphasises the problem for individuals suffering differing demands in terms of roles enacted and how this may produce ambivalence.
\end{abstract}

The paper focuses on the United Kingdom, examining the experience of the bereaved in planning and participating in the funeral of a close member of their social group. In-depth semi-structured interviews lasting 45-60 minutes represented the principal means of data collection, for which an inductive exploratory approach was used (Miles and Huberman, 1994) to identify key themes related to the funeral consumption experience. A total of 21 participants from varied religious and secular backgrounds in the West Midlands responded to invitations to participate that were placed with public institutions. Given the emotional consequence of funerals, the researchers excluded respondents whose experience was within a 12 month period of when the interviews were conducted. In our analysis of the participants' funeral experiences following Carù and Cova, we recognise that we only have access to the experience through our interpretation of what participants' express. Our thematic analysis is built upon the desire to produce a richer understanding of the nature of the consumer experience albeit within a specific and not widely researched area of consumption.

The varied nature of the experience of the participants outlined in the study illustrates the complexity of experience within one consumption field. We accept that funeral consumption is a relatively unusual subject in consumer research, but it is a common human experience worthy of examination and this study provides an exemplar of the complexity and ambivalence inherent therein.

References available on request 